\title{
Kai M. Siegbahn (1918-2007): a pioneer in high-resolution electron spectroscopy
}

\author{
Magdolna Hargittai ${ }^{1}$
}

Accepted: 8 December 2021 / Published online: 12 January 2022

(c) The Author(s), under exclusive licence to Springer Science+Business Media, LLC, part of Springer Nature 2021

\begin{abstract}
Kai M. Siegbahn (1918-2007), Professor of Physics at Uppsala University, was one of the pioneers of high-resolution electron spectroscopy. He was awarded half of the physics Nobel Prize in 1981. In 2001, he spoke about the circumstances of his invention of ESCA, about his research over his long career in science, and about the influence of his father, Manne Siegbahn. I am sharing excerpts from our recorded conversation, 15 years after his death.
\end{abstract}

Keywords Kai Siegbahn · Manne Siegbahn · High-resolution electron spectroscopy $\cdot$ ESCA $\cdot$ Angstrom Laboratory

The name of Siegbahn et al. (1918-2007, Figs. 1 and 2) has been associated with high-resolution electron spectroscopy and specifically with electron spectroscopy for chemical analysis, ESCA. The phenomena utilized in this technique go back to Albert Einstein's discovery of the photoelectric effect-the emission of electrons from a metal surface irradiated with light of short wavelength. When a high-energy photon, generated, for example, from an X-ray source, hits an atom and penetrates its deep inside, an electron may be emitted. The analysis of this expelled electron may yield important information about the inside of the atom which emitted it. The early experiments did not show much promise for practical applications, but from the 1950s, Kai Siegbahn and his colleagues built and gradually perfected instrumentation, which was capable of yielding valuable information about the source atoms in such experiments. Thus, the ESCA technique developed and sophisticated commercial instrumentation spread around the world in numerous laboratories. Kai Siegbahn was awarded half of the 1981 physics Nobel Prize for his contribution to this novel technique. The other half went jointly to Nicolaas Bloembergen and Arthur L. Schawlow for related discoveries, "for their contribution to the development of laser spectroscopy."

Twenty years after Kai M. Siegbahn's discovery, I visited him in his laboratory at Uppsala University and we recorded

Magdolna Hargittai

hargittaim@gmail.com

1 Budapest University of Technology and Economics, Budapest 1521, Hungary a conversation from which I am sharing a few excerpts with the readers of Structural Chemistry. Kai Siegbahn was born in Lund, Sweden. He studied physics, mathematics, and chemistry at Uppsala University and received his doctorate in 1944. He worked at the Nobel Institute for Physics in 1942-1951, at the Royal Institute of Technology in Stockholm in 1951-1954, and joined Uppsala University in 1954 where he stayed for the rest of his career.

Our meeting took place at the Angstrom Laboratory on March 9, 2001. We recorded our conversation during which Dr. Siegbahn was showing a variety of physical experiments in the laboratory. Below, I am quoting from his narrative about his research over the decades. I find it interesting not only for its factual material about electron spectroscopy but also about the way research was being organized and done more than half a century ago:

I am mainly a researcher in surface science. But that was not so from the very beginning. When I completed my studies, nuclear physics was the field and everybody rushed into it. That, of course, had the consequence that other fields were highly neglected then. That was perhaps my luck because when I had been working in nuclear physics for my thesis, I had access to the little cyclotron we had then in Stockholm, where my father [Manne Siegbahn] was the head of the laboratory. This cyclotron was rather capricious, sometimes it had bad vacuum or something else. So from time to time I found myself without a sample to study, but I had developed a high-resolution magnetic spectrometer for low energies, and therefore I thought, 


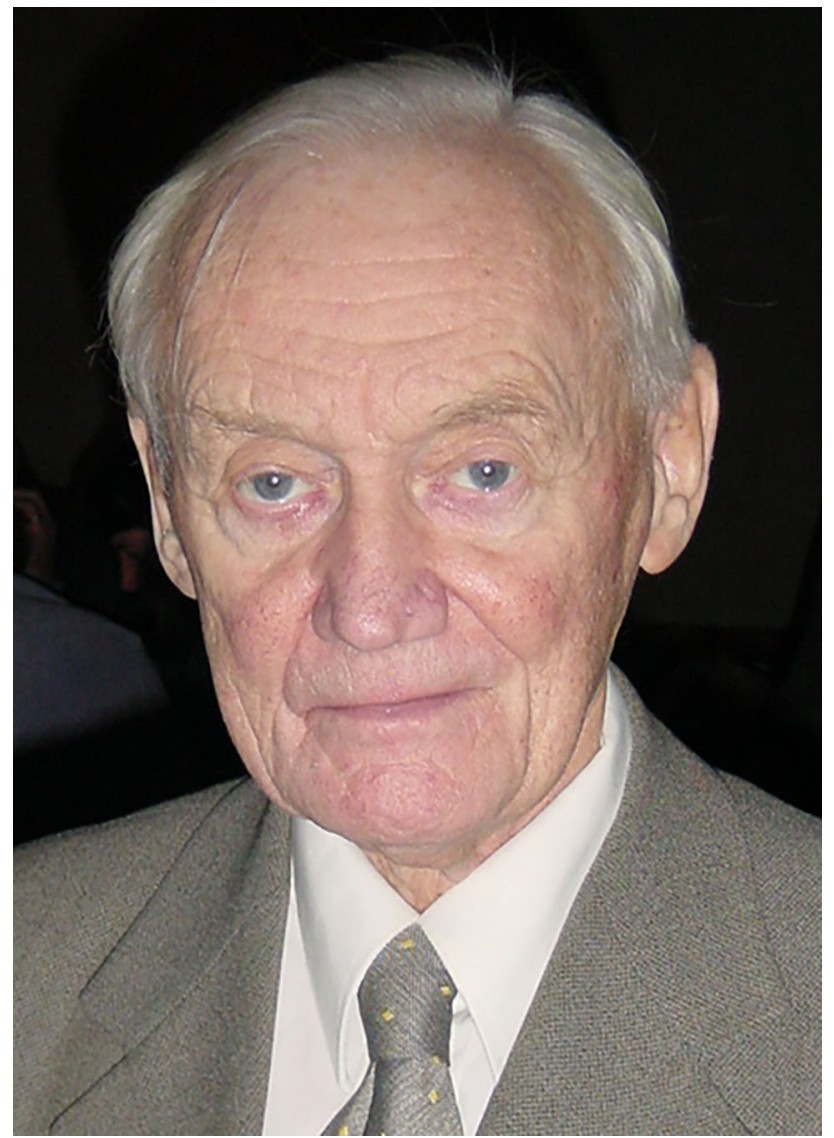

Fig. 1 Kai M. Siegbahn, 2001 in Uppsala, at the Angstrom Laboratory. Photograph by M. Hargittai

maybe I could simulate the radioactive radiation by putting in an X-ray tube and let the X-rays fall on my sample. That took quite some time to build because if I wanted to get some chemically important results, I had to go from very high energies to much lower energies, about a thousand times lower, without losing my resolution. Also, the detector for this very soft X-ray radiation was a problem. Our Geiger-Müller counter, which was the only one at that time, was made from very thin tin foils, which were leaking all the time, so I had to compensate for the leakage. Of course, we had no computer at that time. When our apparatus was ready to test, it was when I had to come to Uppsala because there was a professorship opening up here.

I had two assistants, who started to do their doctorate work and I promised them, here we have this new machine, which operates now. So we took something from the shelves, some chemicals to put in the machine, but we did not see anything! Absolutely nothing. These two young people looked at me very suspiciously. Then I put together, with my students, an evaporation set in the vacuum, for a sample of copper.

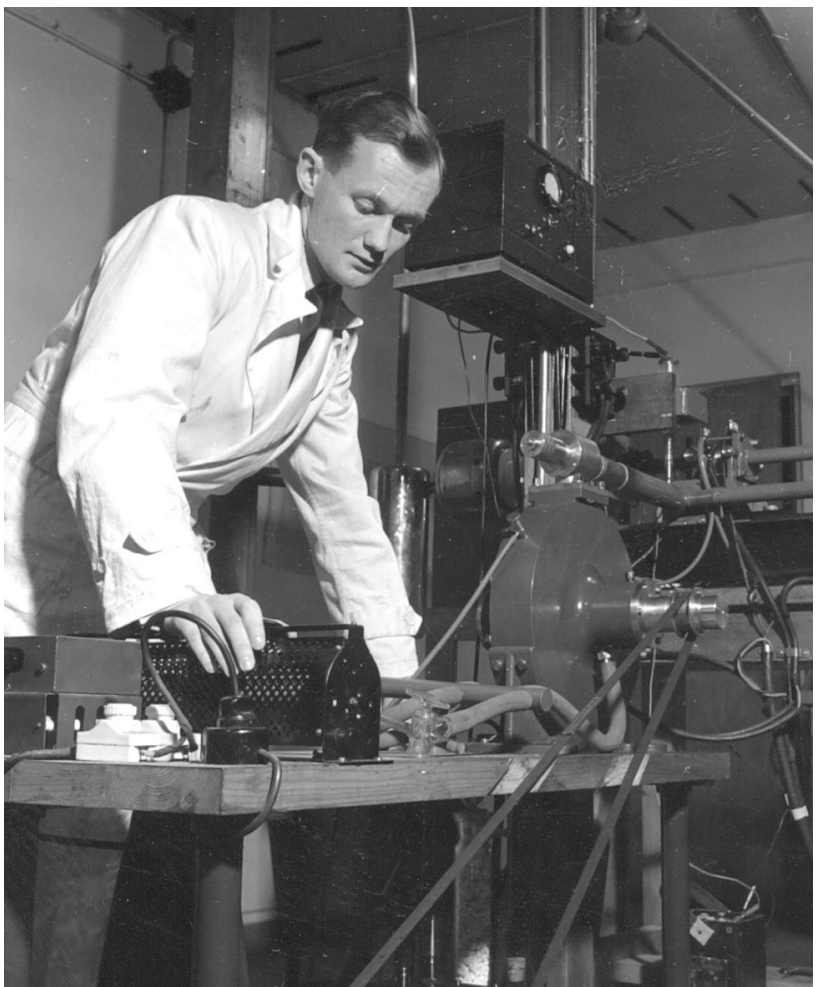

Fig. 2 Kai Siegbahn in his laboratory at Uppsala University. Courtesy of Kai Siegbahn

Then we got to see all the lines. I still remember that evening when we saw this, and later at home my wife opened a bottle of Champaign to celebrate this. Of course, then we understood that from now on we can put almost anything into our apparatus.

Very soon the number of graduate students increased a lot because they understood that if they worked here they could get their thesis done easily. It was great fun for all of us because almost everything we touched upon was new. We saw chemical shifts, we saw spinorbit splitting of the electron lines, and we saw that it was the surface what mattered. It was less than one percent of an atomic layer sufficient to see the spectrum. This was a wonderful time.

We collected a rather large amount of material. We published our findings; very strangely, in the journal of our academy. Only members of our academy and professors in Swedish universities were allowed to publish their findings there, but it took more than 2 years for our papers to appear. So for quite a time nobody knew about what we were doing. Later, we sent a letter to Physical Review when we saw that the line width was in the electron volts' region rather than in kilovolts. That letter was published, but evidently it was still not noticed. So we continued and the number of people working in my laboratory kept increasing. Then, we decided 
that we should try to write a book about this new spectroscopy. We organized our work at the spectrometer in shifts; we worked $24 \mathrm{~h}$ and weekends; there were night shifts, weekend shifts, etc. At the end of 1 year we had so much material that we decided to start writing the book about it $[1,2]$. This is a brief summary of the story.

Then, we have improved our technique and the equipment, introduced focal planes, we could take many lines simultaneously, we introduced the rotating X-ray anodes, convenient for this purpose, and we were able to increase intensity more than a thousand times, which enabled us to record spectra much more quickly. We introduced monochromatized radiation by X-ray diffraction on crystals. Aluminum $\mathrm{K} \alpha$ radiation was particularly useful, which happened to fit very nicely to certain planes in quartz crystals. We also bent it to get the point focus. So this is briefly the development of electron spectroscopy for chemical analysis, ESCA.

We have been working much with X-rays in my laboratory. This was quite natural because this laboratory had originated with my father and my father's generation who was much more interested in X-rays than in nuclear physics. My father had gone through all the elements with X-ray spectroscopy and increased the resolution very much, indeed. He had also written a book about this. After that, he thought that he had done what he needed to do for X-ray spectroscopy and went on to nuclear physics and built the first cyclotron in Sweden. That time, we did not have any research councils, so he had to go to the Academy for money, and they had a little more money that time, and thus he moved to Stockholm.

Manne Siegbahn (1886-1978, Fig. 3), Kai Siegbahn's father, was awarded the Nobel Prize in Physics in 1924 "for his discoveries and research in the field of X-ray spectroscopy" when Kai was 6 years old. In 2001, he remembered the excitement of the time. He and his brother received new shoes and clothes; they had to comb their hair, before going to the Music Academy, where the award-giving ceremony took place. The boys expected a sack of gold, so there was some disappointment, but their greatest disappointment was to see the King without his crown on his head. Manne Siegbahn had a lot to do with Kai's becoming a physicist. The father used to ask him to go along when he went to his laboratory on Sundays. He showed everything to Kai who enjoyed especially the colorful spectra his father projected onto the fall of the laboratory. Kai became very much interested in what his father was doing. In his words: "I enjoyed it almost as much, not quite but almost, as playing football. I decided that I would like to do the same thing as my father. That was an early decision and I was interested in physics, mathematics, chemistry, and so on. I had an older brother, but he was not interested in Father's work, so he did not follow him into the lab. He went on to study law and he later became a diplomat."

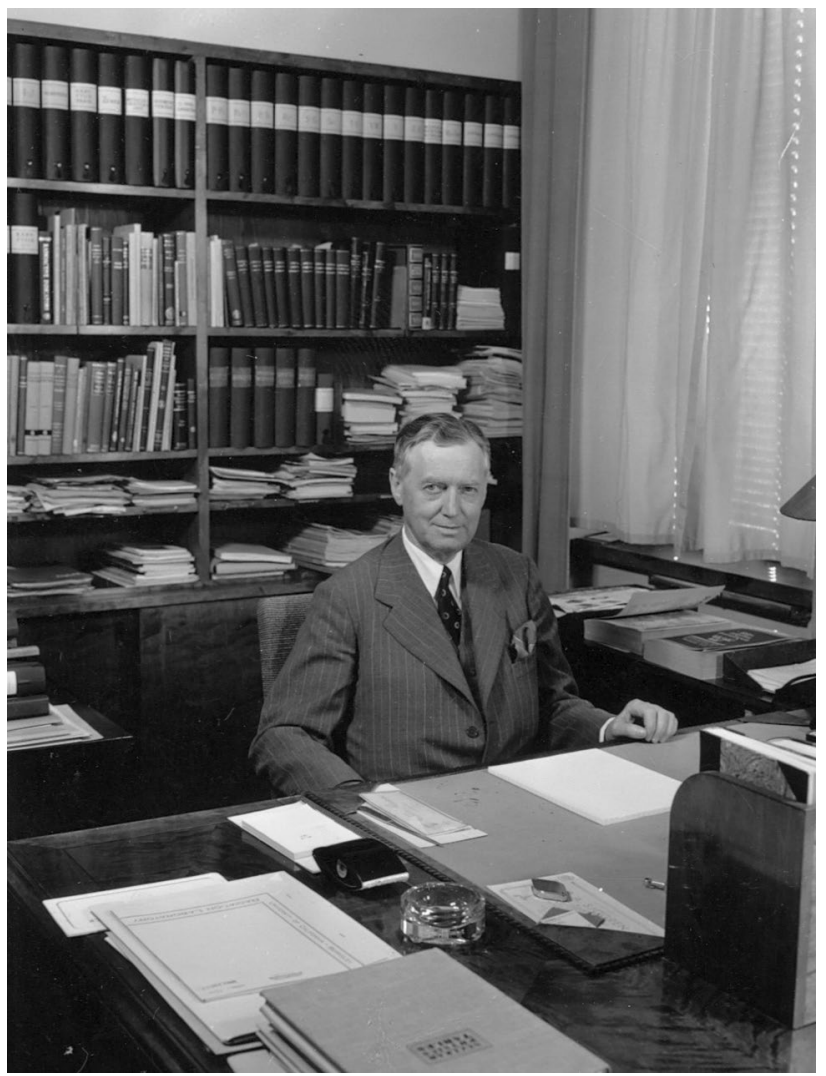

Fig. 3 Manne Siegbahn in his office. Courtesy of Kai Siegbahn

Growing up in Manne Siegbahn's family for a budding scientist was a unique experience because Manne Siegbahn was such a central figure in international science at the time: "My father had very strong connections with famous scientists. For example, when they came to Sweden to receive their Nobel Prizes, they always visited my father in our home. I saw many of the most famous scientists of those times through the keyhole at home. Later I could have some conversations with them. I remember when my parents went down to the railway station of Uppsala to fetch Carl Anderson, the discoverer of positron. I was at home. As it happened, my parents and Anderson did not find each other at the railway station and Anderson came directly to our home. He rang the bell, I opened the door, I welcomed him, we sat down, and I had the responsibility to entertain Anderson for a rather long time before my parents returned home. Later I met Anderson in the United States and he still remembered how we were sitting together and talking to each other. $\mathrm{He}$ received the Nobel Prize in 1936, so I was 18 years old at that time."

Furthermore, Kai told me about his father: "He was a quiet man and he had high respect. At that time parents had great authority. He was nice and showed interest in what we were doing, but he was very much occupied by his research. 
So we did not meet so much, except for meals. Later on, when I myself started to do research, he became very interested in what I was doing, we discussed it, and when he got very, very old, he lived until 92 years of age, ... he remembered his physics, and we could talk about physics like in the old times."

Kai Siegbahn and his wife had three sons, and he told me about the work of one of them; Per, who was born in 1945, and became a theoretical physicist. Hans (b. 1947) also became a physicist and Nils (b. 1953) became a biochemist. So there were at least three generations of physicists among the Siegbahns, forming a physicist dynasty. When we had our conversation, Kai Siegbahn was already 83 years old and still kept going to the laboratory. One of his outside interests was also related to science. For some 40 years, he ran an international school of physics for students from emerging countries with about 15 students annually. Some of the students stayed on in Sweden through their doctoral studies. This was an important contribution to international science, but Kai Siegbahn still thought that his single most important contribution was the development of electron spectroscopy.
Acknowledgements I thank Hans Siegbahn, Professor of Physics, Uppsala University, for his assistance in the finalization of the manuscript.

\section{Reference}

1. Siegbahn K, Nordling C, Johansson G, Hedman J, Hedén PF, Hamrin K, Gelius U, Bergmark T, Werme LO, Manne R, Baer Y (1967) ESCA - atomic, molecular and solid state structure studied by means of electron spectroscopy. Nova Acta Regiae Soc Sci Upsaliensis Ser IV Vol 20

2. Siegbahn K, Nordling C, Johansson G, Hedman J, Hedén PF, Hamrin K, Gelius U, Bergmark T, Werme LO, Manne R, Baer Y (1969) ESCA applied to free molecules north-holland. Publ Co Amster London

Publisher's Note Springer Nature remains neutral with regard to jurisdictional claims in published maps and institutional affiliations. 